\title{
Progress in Vinyl Acetate
}

\author{
Heng Ma \\ School of Chemical Engineering, Qingdao University of Science and Technology, Qingdao, Shandong, \\ China
}

\begin{abstract}
Vinyl acetate is an organic chemical raw material of great industrial value. It is widely used in synthetic film, adhesive, coating and textile slurry. The production route of vinyl acetate is introduced, and the advantages and disadvantages of synthesis methods of vinyl acetate method, acetylene method, EDA cracking method, base synthesis method and Halcon method are compared. The method of carbide acetylene has high economic efficiency, low energy consumption and good environmental protection, proposing the development direction of ethylene acetate production technology.
\end{abstract}

Keywords:Vinyl acetate, production process, calcium carbide acetylene method, gas-phase ethylene method, yield

\section{I.Introduction}

Vinyl acetate, with a boiling point of $72^{\circ} \mathrm{C}-73^{\circ} \mathrm{C}$, is a colorless flammable liquid, insoluble in water, but soluble in most organic solvents such as alcohol. Vinyl acetate is an important organic chemical raw material with large output at present, which can be used in organic synthesis. It is mainly used in industry to synthesize a series of chemical fiber and chemical products ${ }^{[1]}$ such as binder, vinylon, polyvinyl alcohol, film, acetal resin, coating and paper reinforcing agent. At present, there is more research ${ }^{[2-3]}$ on the technical comparison of vinyl acetate production by ethylene method and acetylene method, and less research on new synthesis methods such as EDA cracking method and carbonyl synthesis method.

In this paper, the production process of vinyl acetate is introduced comprehensively. Compared with previous studies, this paper comprehensively compares the advantages and disadvantages of various synthetic processes of vinyl acetate such as calcium carbide acetylene method and gas-phase ethylene method from the aspects of industrial application, process complexity, energy consumption, conversion rate and product quality. Compared with previous studies, it supplements the analysis and comparison of new production processes such as EDA cracking method and carbonyl synthesis method, and analyzes each process in detail from the aspects of product quality, energy consumption, conversion rate and process complexity, and puts forward the development prospect of vinyl acetate production technology in the future, providing theoretical reference and basis for industrial production of vinyl acetate.

\section{Production Method of Vinyl Acetate}

The production technology of vinyl acetate has experienced a century's development. At present, its synthesis methods mainly include ethylene method, acetylene method, EDA cracking method, carbonyl synthesis method, etc. The acetylene method includes natural gas acetylene method and calcium carbide acetylene method. At present, the production technology of acetylene method has been improved, but it is still immature, and the source of acetylene is limited. Ethylene process has become the main method of vinyl acetate production, and has broad development prospects. At present, ethylene method and acetylene method have gradually occupied a dominant position in domestic and foreign markets, while EDA cracking method, carbonyl synthesis method and Halcon method are new processes, which are all in the experimental stage and have not been applied to industrial production on a large scale.

\subsection{Acetylene process}

ISSN: 0010-8189 
Acetylene method includes gas-phase method and liquid-phase method, but liquid-phase method is not used because of its many by-products and low conversion rate. Gas-phase method is the main production method in domestic enterprises. Acetylene gas-phase method uses activated carbon as catalyst, and at proper temperature, acetylene reacts with acetic acid vapor to produce vinyl acetate. Acetylene gas phase method can be divided into natural gas acetylene method and calcium carbide acetylene method according to different raw materials.

\subsubsection{Natural gas acetylene method}

The natural gas acetylene method uses natural gas as raw material. Firstly, it is partially oxidized to synthesize acetylene, then acetic acid is synthesized by using the synthesis gas. After that, vinyl acetate can be prepared by gas-solid catalytic reaction. The natural gas acetylene process mainly includes three parts: (1) Preparation of acetylene, in which natural gas is subjected to $\mathrm{S}$ removal and partial oxidation to prepare acetylene for purification.

(2) Reacting the prepared acetylene and acetic acid under suitable conditions to generate vinyl acetate. (3) Refining vinyl acetate to obtain high purity products.

Hu Yigong ${ }^{[4]}$ et al. used synthesis gas and dimethyl ether as raw materials and took acetic acid as solvent to prepare high purity vinyl acetate under high pressure. The optimum reaction conditions were determined. The optimum reaction temperature, pressure and time were $180^{\circ} \mathrm{C}, 4.6 \mathrm{MPa}$ and $5 \mathrm{~h}$, respectively, and the molar ratio of carbon monoxide to hydrogen was 1 . This process uses acetic acid as absorbent, which improves the recovery rate of acetylene and has relatively low operating cost; the defects of this method are complex production process, high equipment investment and operation cost, and poor economy.

\subsubsection{Calcium carbide acetylene method}

Calcium carbide acetylene method is to use calcium carbide and water as raw materials to synthesize acetylene first, and purify acetylene gas by removing $\mathrm{S}$ and $\mathrm{P}$ with activated carbon-zinc acetate as catalyst to produce high-purity vinyl acetate under specific reaction conditions. At present, the production process of vinyl acetate in fixed-bed reactor is relatively mature, while fluidized-bed reactor is gradually used in the actual production of vinyl acetate because of its advantages of convenient catalyst replacement, uniform mixing and controllable temperature. However, the disadvantages of fluidized bed technology lie in large back mixing, rapid aging and frequent replacement of catalyst, which reduces the benefits in actual production. Figure 1 is a schematic diagram of the process flow of vinyl acetate by calcium carbide method.

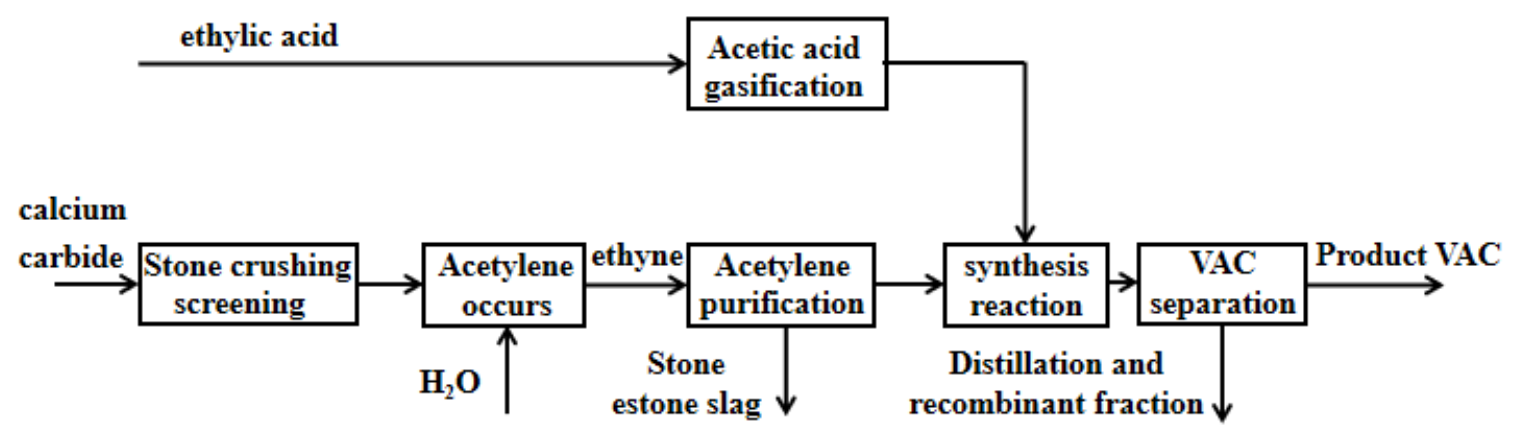

Figure 1 Process flow diagram of vinyl acetate production by calcium carbide method

At present, new catalyst materials and catalyst structure improvement are the research hotspots of this process. Guo Xiuling ${ }^{[5]}$ et al. synthesized a bamboo activated carbon catalyst and applied it to the synthesis of vinyl acetate by calcium carbide method. The performance of the catalyst was evaluated in a fixed bed reactor, and the bamboo activated carbon catalyst was improved to provide a new type of high activity catalyst. Wang Qinwang ${ }^{[6]}$ improved the system of synthesizing vinyl acetate by calcium carbide acetylene method from two aspects of increasing catalyst load and adjusting reactor size, which increased the capacity of producing vinyl acetate, increased the output of vinyl acetate by $25 \%$, and greatly reduced energy consumption. Meng Linghu ${ }^{[7]}$ et al. simulated and optimized the technological process of producing vinyl acetate by calcium carbide method, which made the mass fraction of vinyl acetate and acetic acid reach $99.94 \%$ and $99.62 \%$ respectively. The optimized process greatly improved the 
product quality.

\subsection{Ethylene process}

Ethylene process can be divided into gas-phase process and liquid-phase process. In liquid-phase process, $\mathrm{PdCl}_{2}$ is generally used as catalyst, but $\mathrm{Cl}$ - in it is corrosive to equipment. This process damages the equipment to a certain extent and has been gradually abandoned. Gas-phase ethylene process is widely used in vinyl acetate production at home and abroad because of its excellent characteristics. Gas-phase ethylene method is to use acetic acid, oxygen and ethylene as raw materials, select Pd-Pt and other metal catalysts, and generate crude vinyl acetate in a gas-solid catalytic fixed bed reactor under the reaction conditions of $110{ }^{\circ} \mathrm{C}-200^{\circ} \mathrm{C}$ and $0.7 \mathrm{MPa}-0.9 \mathrm{MPa}$, and obtain high-purity vinyl acetate after separation and refining. Gas-phase ethylene method has the advantages of higher catalyst activity, better reaction selectivity, higher yield, economy and environmental protection, so it has gradually become the mainstream process for synthesizing vinyl acetate. The following is the reaction equation for synthesizing vinyl acetate by ethylene method:

(1) main reaction:

$$
\mathrm{C}_{2} \mathrm{H}_{4}+\frac{1}{2} \mathrm{O}_{2}+\mathrm{CH}_{3} \mathrm{COOH} \rightarrow \mathrm{CH}_{3} \mathrm{COOCHCH}_{2}+\mathrm{H}_{2} \mathrm{O}
$$

(2) side reaction:

$$
\begin{gathered}
\mathrm{C}_{2} \mathrm{H}_{4}+\frac{1}{2} \mathrm{O}_{2}=\mathrm{CH}_{3} \mathrm{CHO} \\
\mathrm{CH}_{3} \mathrm{COOH}+2 \mathrm{O}_{2} \rightarrow 2 \mathrm{CO}_{2}+2 \mathrm{H}_{2} \mathrm{O} \\
\mathrm{C}_{2} \mathrm{H}_{4}+\mathrm{CH}_{3} \mathrm{COOH}=\mathrm{CH}_{3} \mathrm{COOC}_{2} \mathrm{H}_{5} \\
2 \mathrm{C}_{2} \mathrm{H}_{4}+2 \mathrm{CH}_{3} \mathrm{COOH}+3 \mathrm{O}_{2}=2 \mathrm{CH}_{3} \mathrm{COOCH}_{3}+2 \mathrm{H}_{2} \mathrm{O}+2 \mathrm{CO}_{2} \\
2 \mathrm{C}_{2} \mathrm{H}_{4}+2 \mathrm{CH}_{3} \mathrm{COOH}+3 \mathrm{O}_{2}=2 \mathrm{CH}_{2} \mathrm{CHCHO}+4 \mathrm{H}_{2} \mathrm{O}+2 \mathrm{CO}_{2} \\
2 \mathrm{C}_{2} \mathrm{H}_{4}+4 \mathrm{CH}_{3} \mathrm{COOH}+\mathrm{O}_{2}=2\left(\mathrm{CH}_{3} \mathrm{COO}\right)_{2} \mathrm{C}_{2} \mathrm{H}_{4}+2 \mathrm{H}_{2} \mathrm{O}
\end{gathered}
$$

Guo ting ${ }^{[8]}$ et al. selected different supports and prepared different types of Pd-Au catalysts by volume impregnation method, and explored the influence mechanism of different reaction conditions on the catalytic performance of the catalysts. when the temperature was $154^{\circ} \mathrm{C}$, the space time of Pd-Au supported catalyst was $706 \mathrm{~g}(1 \mathrm{~h})-1$, at which the yield of vinyl acetate was the highest and the selectivity of acetic acid was $93 \%$. Hu Hualin et al. ${ }^{[9]}$ also prepared $\mathrm{Pd}-\mathrm{Au}$ catalyst supported on modified activated carbon by volume impregnation method, and investigated the catalytic activity of the catalyst in ethyl acetate synthesis reaction. It was found that when the mass ratio of palladium to gold was 1.12: 1, the catalyst loading reached the maximum, and the yield of vinyl acetate reached the maximum, which was $94.9 \%$. Zheng Mingshi ${ }^{[10]}$ et al. optimized the process parameters through process simulation, and finally achieved $99.9 \%$ mass fraction of vinyl acetate by ethylene method, which reduced the content of ethyl acetate impurities to below 140ppm. In addition, the amount of recovered steam reached $1254 \mathrm{Kg} / \mathrm{h}$, which greatly reduced energy consumption and equipment cost. Figure 2 is a flow chart of ethylene gas phase synthesis section. 


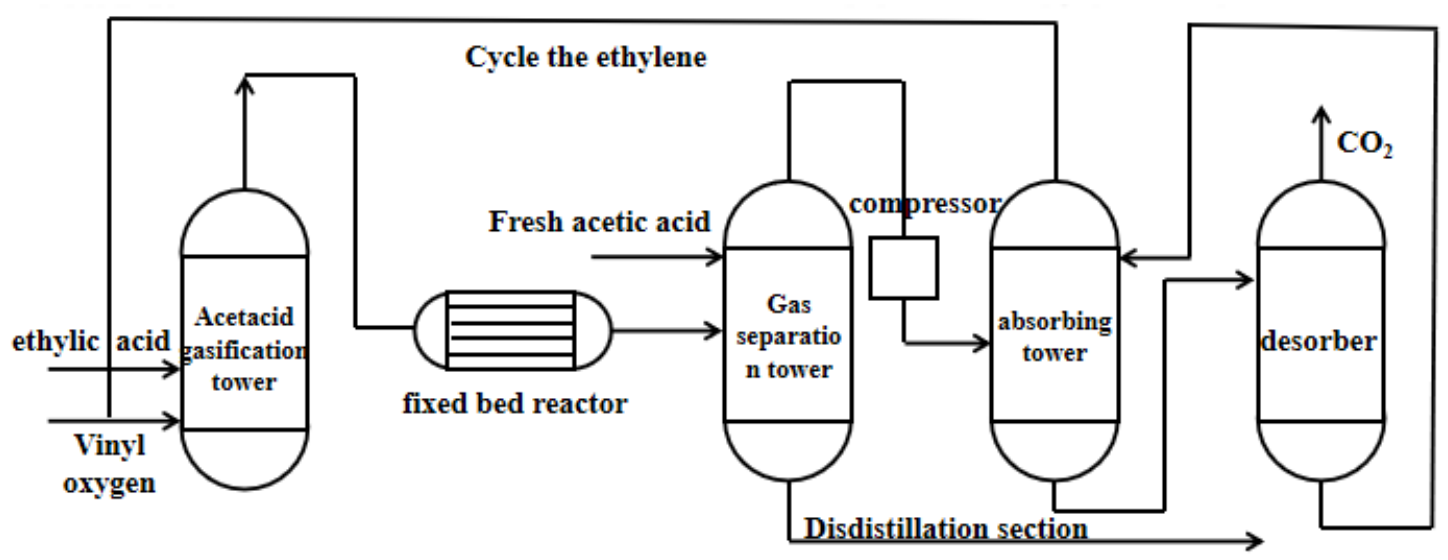

Fig. 2 Flow chart of ethylene gas-phase synthesis section

\subsection{Other emerging processes}

\subsubsection{Carbonyl synthesis method}

Using coal as raw material, synthesis gas can be prepared to obtain methanol, and acetic anhydride can be produced by methanol carbonylation treatment. On the basis of this production route, some scholars ${ }^{[11]}$ have studied the route of using methanol carbonylation to synthesize vinyl acetate. That is, methanol and acetic acid synthesize methyl acetate under specific conditions, and methyl acetate further reacts with carbon monoxide and hydrogen to synthesize ethyl acetate. Finally, ethyl acetate is decomposed to obtain ethyl acetate. In this process, the reaction of methyl acetate with carbon monoxide and hydrogen is the most important. Under the reaction conditions including a temperature of $178^{\circ} \mathrm{C}$ and a pressure of $5 \mathrm{MPa}$, using methyl iodide as catalyst, the conversion rate of methyl acetate can reach $43.8 \%$, and the yield of ethyl acetate can reach $89 \%$. With benzene sulfonic acid as catalyst, the yield of vinyl acetate can reach $86.9 \%$ under the same reaction conditions.

The reaction equation of this process is as follows:

$$
\begin{gathered}
2 \mathrm{CH}_{3} \mathrm{OH}+2 \mathrm{CH}_{3} \mathrm{COOH} \rightarrow 2 \mathrm{CH}_{3} \mathrm{COOCH}_{3}+2 \mathrm{H}_{2} \mathrm{O} \\
2 \mathrm{CH}_{3} \mathrm{COOCH}_{3}+2 \mathrm{CO}+\mathrm{H}_{2} \rightarrow \mathrm{CH}_{3} \mathrm{CH}_{\left(\mathrm{CH}_{2} \mathrm{COO}\right)_{2}+\mathrm{CH}_{3} \mathrm{COOH}} \\
\mathrm{CH}_{3} \mathrm{CH}\left(\mathrm{CH}_{2} \mathrm{COO}\right)_{2} \rightarrow \mathrm{CH}_{3} \mathrm{COOCHCH}_{2}+2 \mathrm{H}_{2} \mathrm{O}
\end{gathered}
$$

Total reaction:

$$
2 \mathrm{CH}_{3} \mathrm{OH}+2 \mathrm{CO}+\mathrm{H}_{2} \rightarrow \mathrm{CH}_{3} \mathrm{COOCHCH}_{2}+2 \mathrm{H}_{2} \mathrm{O}
$$

Carbonylation method uses methanol, $\mathrm{CO}$ and $\mathrm{H}_{2}$ as reactants, instead of acetic acid, ethylene and acetylene, and uses coal as the initial raw material to synthesize ethyl acetate by carbonylation. It is a new production process. However, this process is a new production process of ethyl acetate, with immature technology and high operating cost. It has not been widely used in industrial production yet.

\subsubsection{EDA cracking method}

EDA cracking method uses methanol as raw material. The methanol undergoes esterification reaction under the action of acetic acid to produce methyl acetate, which then undergoes hydroformylation reaction to synthesize ethylene diacetate (EDA). Finally, ethylene diacetate is cracked to obtain ethyl acetate. EDA cracking method has important industrial application value because of its better atomic economy.

The reaction equation of this process is as follows:

$$
\begin{gathered}
\mathrm{CH}_{3} \mathrm{OH}+\mathrm{CH}_{3} \mathrm{COOH} \rightarrow \mathrm{CH}_{3} \mathrm{COOCH}_{3}+\mathrm{H}_{2} \mathrm{O}(1) \\
2 \mathrm{CH}_{3} \mathrm{COOCH}_{3}+2 \mathrm{CO}+\mathrm{H}_{2} \rightarrow \mathrm{CH}_{3} \mathrm{CH}\left(\mathrm{OCOCH}_{3}\right)_{2}+\mathrm{CH}_{3} \mathrm{COOH}(2)
\end{gathered}
$$

ISSN: 0010-8189 


$$
\begin{gathered}
\left(\mathrm{CH}_{3} \mathrm{CO}_{2}\right)_{2} \mathrm{CHCH}_{3} \leftrightarrow \mathrm{CH}_{3} \mathrm{COOCH}=\mathrm{CH}_{2}+\mathrm{CH}_{3} \mathrm{COOH}(3) \\
\left(\mathrm{CH}_{3} \mathrm{CO}_{2}\right)_{2} \mathrm{CHCH}_{3} \leftrightarrow\left(\mathrm{CH}_{3} \mathrm{CO}\right)_{2} \mathrm{O}+\mathrm{CH}_{3} \mathrm{CHO}(4) \\
\mathrm{CH}_{3} \mathrm{COOCH}=\mathrm{CH}_{2}+\mathrm{H}_{2} \mathrm{O} \rightarrow \mathrm{CH}_{3} \mathrm{COOH}+\mathrm{CH}_{3} \mathrm{CHO}(5)
\end{gathered}
$$

Some scholars ${ }^{[12]}$ used methyl iodide as catalyst under the reaction conditions of a temperature of $178^{\circ} \mathrm{C}$ and a pressure of $5.15 \mathrm{MPa}$, so that the conversion rate of methyl acetate reached $43 \%$ and the yield of EDA reached $88.3 \%$. When the ratio of EDA to acetic anhydride in fixed feed was 1: 4 and benzene sulfonic acid was used as catalyst, the mass fraction of vinyl acetate was $72 \%$. This process has good atomic economy. There are no three wastes produced in the reaction process, and the intermediate products are effectively utilized. But this process is still in the laboratory test stage.

\section{Comparative Analysis of Synthesis Process of Vinyl Acetate}

At present, the methods used in industrial production include acetylene method and ethylene method, while carbonyl synthesis method and EDA cracking method are now in the laboratory research stage with immature technology. The following part focuses on the comparative analysis of acetylene method and gas-phase ethylene method. From the industrial application point of view, the gas-phase ethylene method has gradually replaced the acetylene method, with broad development prospects. Seen from the complexity of the process, the acetylene process is cumbersome, while the ethylene process is short with relatively low equipment cost and operation cost. In terms of energy consumption, acetylene method has relatively high energy consumption, while ethylene method has relatively low energy consumption. In addition, the conversion rate, product quality and environmental protection of the two

\begin{tabular}{|c|c|c|}
\hline Indicator & $\begin{array}{c}\text { wacker、borden } \\
\text { Calcium carbide acetylene method and natural } \\
\text { gas acetylene method }\end{array}$ & Gas-phase ethylene method \\
\hline $\begin{array}{l}\text { Industrial } \\
\text { application }\end{array}$ & $\begin{array}{l}\text { With the serious aging of the production } \\
\text { equipment, the maintenance becomes difficult. } \\
\text { There are higher environmental requirements, } \\
\text { causing less industrial application }\end{array}$ & $\begin{array}{l}\text { Industrial applications are gradually } \\
\text { increasing, with production } \\
\text { capacity above } 10 \mathrm{wt} .\end{array}$ \\
\hline Cost & $\begin{array}{l}\text { The price increase of calcium carbide, the main } \\
\text { raw material, has led to an increase in costs }\end{array}$ & $\begin{array}{c}\text { Smaller environmental treatment } \\
\text { capacity and less waste treatment } \\
\text { cost }\end{array}$ \\
\hline $\begin{array}{l}\text { Process } \\
\text { complexity }\end{array}$ & $\begin{array}{l}\text { The process is cumbersome, and the equipment } \\
\text { cost and operation cost are high }\end{array}$ & $\begin{array}{l}\text { The process is short, and the } \\
\text { equipment cost and operation cost } \\
\text { are low }\end{array}$ \\
\hline $\begin{array}{l}\text { Conversion } \\
\text { rate }\end{array}$ & $10 \% \sim 11 \%$ (calculated by acetylene) & $11 \%$ (calculated by acetylene) \\
\hline $\begin{array}{c}\text { Energy } \\
\text { consumption }\end{array}$ & Relatively high & Relatively low \\
\hline $\begin{array}{l}\text { Product } \\
\text { quality }\end{array}$ & $\begin{array}{l}\text { Aldehydes produced in the production process } \\
\text { will affect the quality of the final vinyl acetate } \\
\text { product }\end{array}$ & $\begin{array}{c}\text { No harmful substances produced in } \\
\text { the process, with small influence on } \\
\text { products }\end{array}$ \\
\hline $\begin{array}{l}\text { Environment } \\
\text { al } \\
\text { conservation }\end{array}$ & Poor, great pollution to the environment & $\begin{array}{l}\text { Good, less pollution to the } \\
\text { environment }\end{array}$ \\
\hline
\end{tabular}
processes are compared and analyzed, and the specific data are shown in Table 1.

Table 1 Comparison of production methods of vinyl acetate

At present, China has raised increasingly high requirements of low energy consumption and environmental protection for enterprises. Comprehensive analysis shows that acetylene method has relatively low conversion rate, high energy consumption and serious pollution, while gas-phase ethylene method is gradually applied to large-scale 
production because of its short process flow, low energy consumption, effective environmental protection, good selectivity and low cost. The gas-phase ethylene method is the main development direction in the future ${ }^{[13-14]}$. Aiming at calcium carbide acetylene method, the future development direction lies in solving the problem of three wastes treatment in the process, developing and improving the production process of raw material calcium carbide and reducing the production cost, such as further developing new technologies like dry acetylene. The future development direction of gas-phase ethylene method lies in developing catalysts with higher catalytic activity and stability, further optimizing the production process of fluidized bed reactor, and realizing the large-scale and industrial production of vinyl acetate. For the new production processes such as oxo-synthesis and EDA cracking, laboratory research and development should be further strengthened to gradually apply them to industrial production and realize the diversification of vinyl acetate production processes.

\section{Conclusions}

Vinyl acetate is an important organic chemical raw material, which is widely used in the synthesis of vinylon, film, acetal resin, coatings and other industrial products, and has important industrial application value. The synthetic route of vinyl acetate is directly related to the quality of the final product, so it is particularly important to choose the appropriate production route. The improvement of vinyl acetate synthesis route is a research hotspot in this field. At present, the research mainly focuses on reducing equipment cost and energy consumption, improving product quality and reducing three wastes. In this paper, the basic contents of vinyl acetate synthesis methods, such as ethylene method, acetylene method, EDA cracking method and carbonyl synthesis method, are introduced, and the advantages and disadvantages of each process route are compared in detail. In terms of industrial application, cost, process complexity, product quality, conversion rate, energy consumption and environmental protection, the synthesis of vinyl acetate by gas-phase ethylene method has great advantages. At present, the gas-phase ethylene process has been gradually applied to the industrial production of vinyl acetate, and most foreign vinyl acetate production enterprises adopt the gas-phase ethylene process. One of the future research directions is to develop new vinyl acetate production processes.

To reduce the process energy consumption and achieve the goal of energy saving and environmental protection, we should continuously explore catalytic materials with better catalytic performance and explore more advanced production routes of vinyl acetate in the future.

\section{References}

[1] Y.Q.Huang, H.Chen, “Comparison of vinyl acetate production processes,” Shandong Chemical Industry, vol. 49, no. 13, pp. 57-60, 2020.

[2] X.Z.Xu, M.Zhang, "Research progress of vinyl acetate production by acetylene," Anhui Chemical Industry, vol. 45, no. 02, pp. 17-20, 2019.

[3] Y.Q.Huang, H.Chen, “Comparison of vinyl acetate production processes," Shandong Chemical Industry, vol. 49, no. 13, pp. 57-60, 2020.

[4] Y.G.Hu, X.F.Lu, D.H.Liu, D.Y.Fang, Y.Jia, C.H.Feng, Y.Z.Gao, J.J.Yan, X.H.Huang, "Study on the preparation of vinyl acetate from dimethyl ether and syngas," Natural Gas Chemical Industry, vol. 40, no. 04, pp. 1-5, 2015.

[5] X.L.Guo,"Preparation and catalytic activity of catalysts for vinyl acetate synthesis by acetylene method,'Journal of Qingdao University of Science and Technology, 2017.

[6] Q.W.Wang,"Methods to increase the yield of vinyl acetate synthesized by calcium carbide acetylene process,"Shanxi Chemical Industry, no. 04, pp. 60-62+79, 2004.

[7] L.H.Meng, Z.M.Lang, S.Q.S. Du, H,Y,Su, M.Li, “Simulation and optimization of distillation column for preparing vinyl acetate by calcium carbide acetylene method based on Aspen Plus," Inner Mongolia Petrochemical Industry, vol. 45, no. 09, pp. 13-16, 2019.

[8] T.Guo, "Preparation and performance of catalysts for synthesis of vinyl acetate by gas phase oxidation of 
ethylene," Guangxi Normal University, 2011.

[9] H.L. Hu, "Preparation and characterization of activated carbon surface modification and supported palladium-gold catalyst,” Guangxi Normal University, 2013.

[10] M.S.Zheng,"Simulation and Optimization of Vinyl Acetate Distillation Process and Energy Saving Research," Journal of Beijing University of Chemical Technology, 2020.

[11] C.Liu,"Production of acetic anhydride and vinyl acetate by carbonylation. Modern Chemical Industry, no. 06, pp. 60, 1982.

[12] J.Zhu, “Optimization of vinyl acetate synthesis reaction process," Hebei University of Science and Technology, 2014.

[13] L.Jia,"Study on a new catalyst for synthesis of vinyl acetate by acetylene gas phase method," Zhejiang University, 2003.

[14] Q.Li, M.L.Tao, M.H.Zhang,"Research progress of catalysts for vinyl acetate palladium production from ethylene in gas phase,” Molecular Catalysis, vol. 26, no. 05, pp. 478-485+390, 2012. 